\title{
Numerical path-integration calculation of transport properties of star polymers and theta-DLA aggregates
}

\author{
M.L.Mansfield ${ }^{1}$, J.F.Douglas ${ }^{2}$ \\ 1 Department of Chemistry and Chemical Biology, \\ Stevens Institute of Technology Hoboken, New Jersey 07030, USA \\ 2 Polymers Division, National Institute of Standards and Technology, \\ Gaithersburg, MD 20899, USA
}

Received December 7, 2001

Although the calculation of transport properties of complex-shaped particles (Smołuchowski rate constants for diffusion-limited reactions, Stokes friction coefficient, virial coefficients for conductivity, viscosity and other transport properties) is straightforward in principle, the accurate evaluation of these quantities for objects of general shape is a problem of classic difficulty. In the present paper, we illustrate a recently developed numerical path-integration method to estimate basic transport properties of representative complex-shaped objects having scientific and technological interest (i.e., star polymers and diffusion-limited aggregates without excluded volume interactions). The methodology applies to objects of essentially arbitrary shape and its validation for special geometries, where exact results are known, is described in a previous paper. Here we calculate the electrostatic capacity and electrical polarizability tensor of these model branched polymers and then exploit exact and approximate electrostatichydrodynamic property interrelations to estimate the Stokes translational friction coefficient and the virial coefficients for conductivity and shear viscosity (intrinsic conductivity and viscosity, respectively). Dimensionless ratios of these transport properties and equilibrium measures of particle size (radius of gyration) are considered since these ratios are important experimentally in determining macromolecular topological structure and universality class. We also discuss and illustrate the influence of the branching architecture on the equilibrium charge distribution ("equilibrium measure") of these branched polymers where they are treated as conductors. An unexpected qualitative change in the charge distribution is found with increasing arm number in star polymers that may have important physical consequences.

Key words: Stokes friction, capacity, intrinsic viscosity, branched polymers, path integration, probabilistic potential theory

PACS: 05.40.-a, 05.60.Cd, 36.20.-r, 47.11. + , 66.20.+d, 66.10.Cb, 77.22. $-d$, 87.15. $V_{V}$ 


\section{Introduction}

Many important materials science problems involve boundary value problems with complex-shaped boundaries [1]. Examples include the electrostatic capacity, the Smołuchowski rate constant, and the translational friction coefficient of arbitrary objects [2-5]; the fluid discharge through pipes of arbitrary cross section [6]; virial coefficients for the material properties of suspensions and composites containing particles of complex shape $[7,8]$; and the far-field scattering and the propagation through apertures of both electromagnetic and acoustic radiation [9-14]. In many of these problems, the relevant properties can be cast in terms either of the electrostatic capacity or of the electric or magnetic polarizabilities of the objects [1-14]. In addition to the obvious electromagnetic applications, these latter quantities are encountered in the virial coefficients of the transport properties of inhomogeneous materials [7], and, because they are shape-dependent functionals, in classifications of particle shape $[2,15]$. For example, they permit characterization of gross polymer topology [16], and we anticipate that they can distinguish more subtle topological features such as the knot state of cyclic polymers and the genus of membranes [1].

Current differential equation or finite element methods for calculating the capacity or the polarizability are at best tedious when the boundary is intricate. The numerical path-integration methods discussed elsewhere [1-4,17] are more direct and general, even when applied to complex shapes. They are highly accurate when compared with results for exactly soluble particle geometries [1-4,17]. Therefore, they should be very useful in a host of applications involving radiation scattering, transport, or characterization of particles of elaborate structure (e.g., biological cells, snowflakes, atmospheric dust, particle aggregates in liquid dispersions, synthetic or biological macromolecules in solution).

In this paper, we apply the path-integration methods $[2-4,17]$ to calculate the electrostatic capacity, $C$, the electrical polarizability tensor, $\boldsymbol{\alpha}_{e}$, the friction coefficient, $f$, the intrinsic viscosity, $[\eta]$, and the intrinsic conductivity, $[\sigma]_{\infty}$, of regular star polymers and of aggregates grown under diffusion-limited conditions [18]. As explained elsewhere $[1-4,17]$, these quantities are all obtained, either exactly or with adequate precision, in the same calculation. The influence of branching architecture on the equilibrium charge distribution is also investigated.

\section{Review of hydrodynamic-electrostatic property interrelations}

There are many exact analogies between the hydrodynamics of suspensions and flowing fluids, the electrostatic properties of conducting and insulating objects, and the elasticity of composite materials and elastic shafts under torsion. Table 1 summarizes a number of these. There are also many approximate electrostatichydrodynamic relations. We focus here on two analogies, one between the electrical polarizability tensor $\boldsymbol{\alpha}_{e}$ of a conducting object and the intrinsic viscosity $[\eta]$ of a suspension of rigid objects having the same shape [7], and the other between the electrostatic capacity $C$ of a conducting particle and the translational friction coeffi- 
Table 1. Exact hydrodynamic-electrostatic analogies. Unless otherwise stated, the hydrodynamic-electrostatic analogies apply to objects of arbitrary shape.

\begin{tabular}{|l|l|l|}
\hline \multicolumn{2}{|c|}{ Analogous Properties } & References \\
\hline Hydrodynamic mass tensor M & Magnetic polarizability tensor $\boldsymbol{\alpha}_{M}$ & $7,10,19,20$ \\
\hline $\begin{array}{l}\text { Friction coefficient of a 2-D body } \\
\text { translating normal to its plane }\end{array}$ & Capacitance, C, of the body & 21 \\
\hline $\begin{array}{l}\text { Force required to displace the in- } \\
\text { terface of an elastic material }\end{array}$ & Capacitance, , of the body & 21 \\
\hline $\begin{array}{l}\text { Rotational friction coefficient of } \\
\text { an axisymmetric body }\end{array}$ & $\begin{array}{l}\text { Component of the hydrodynamic } \\
\text { mass tensor, M, about the sym- } \\
\text { metry axis }\end{array}$ & 22 \\
\hline $\begin{array}{l}\text { Elastic strain field in a twisted } \\
\text { elastic bar }\end{array}$ & $\begin{array}{l}\text { Fluid flux and velocity field in a } \\
\text { pipe }\end{array}$ & $6,15,24$ \\
\hline $\begin{array}{l}\text { Flux of an inviscid fluid through } \\
\text { a hole }\end{array}$ & Capacity of the hole & 25,26 \\
\hline Flux of a viscous fluid & Hydrodynamic mass of the hole & 25,26 \\
\hline $\begin{array}{l}\text { Virtual mass density of a flowing } \\
\text { dispersion of bubbles }\end{array}$ & $\begin{array}{l}\text { Conductivity of a dispersion of in- } \\
\text { sulating particles }\end{array}$ & 27 \\
\hline $\begin{array}{l}\text { Modulus increment of a solid } \\
\text { with rigid inclusions }\end{array}$ & $\begin{array}{l}\text { Viscosity increment of a liquid } \\
\text { with rigid inclusions }\end{array}$ & 28 \\
\hline
\end{tabular}

cient $f$ of a Brownian particle having the same shape $[2,3,5]$. The friction coefficient and intrinsic viscosity are widely used in macromolecular characterization, and these hydrodynamic-electrostatic analogies permit their estimation from numerical calculations of $\boldsymbol{\alpha}_{e}$ and $C$. We now review these analogies and establish our notation and the units.

\subsection{Viscosity-conductivity analogies}

The viscosity $\eta$ or the conductivity $\sigma$ of a suspension of rigid particles can be expanded in virial series $[7,8]$,

$$
\begin{aligned}
& \eta(\text { dispersion })=\eta(\text { dispersing fluid })\left[1+[\eta] \phi+\mathrm{O}\left(\phi^{2}\right)\right], \\
& \sigma(\text { dispersion })=\sigma(\text { dispersing fluid })\left[1+[\eta] \phi+\mathrm{O}\left(\phi^{2}\right)\right],
\end{aligned}
$$

where $\phi$ is the particle volume fraction. The virial coefficients are known either as the "intrinsic viscosity," $[\eta]$, or the "intrinsic conductivity," $[\sigma]$. The latter depends on the relative conductivities of the particles and the dispersing fluid, and we can consider the two extreme cases of conducting particles suspended in an insulating fluid, and vice versa; the intrinsic conductivities in these two extremes will be denoted $[\sigma]_{\infty}$ and $[\sigma]_{0}$, respectively. The refractive index, thermal conductivity, dielectric constant, magnetic permeability and other transport properties can also be expressed in comparable virial expansions [7,8,29-31]. 
As is well known, an external electric field $\mathbf{E}$ induces a charge distribution on the surface of a conductor, and the relationship between the field and the induced dipole moment is given by the electrical polarizability tensor $\boldsymbol{\alpha}_{e}$ [32],

$$
\mu=(1 / 4 \pi) \boldsymbol{\alpha}_{e} \cdot \mathbf{E} .
$$

A similar relationship exists between the magnetic moment $\mu_{m}$, the magnetic polarizability $\boldsymbol{\alpha}_{m}$, and the magnetic field M. Conducting particles in an insulating matrix (or insulating particles in a conducting matrix) are also polarized in an applied field, and in the dilute limit the intrinsic conductivity depends on the polarizability tensor, although only the trace is involved if the particles are oriented randomly. The intrinsic conductivities equal $[7,33]$,

$$
[\sigma]_{\infty}=\left[\operatorname{Tr}\left(\boldsymbol{\alpha}_{e}\right) / d V_{p}\right]
$$

and

$$
[\sigma]_{0}=\left[\operatorname{Tr}\left(\boldsymbol{\alpha}_{m}\right) / d V_{p}\right],
$$

where $V_{p}$ is the particle volume and $d$ is the spatial dimension.

A shear field applied to a dilute dispersion of rigid particles induces a stress dipole ("stresslet") field [34] that modifies the effective viscosity of the dispersion. The intrinsic viscosity is obtained as an angular average of the tensor field describing the perturbation of the flow field by the particle inclusion. Douglas and Garboczi [7] noted that a formal angular averaging of the stress dipole describing the hydrodynamic interaction implies $[\eta] \propto[\sigma]_{\infty}$ since the angular average of the Green's function of Stokes equation is the Green's function of Laplace's equation. The constant of proportionality is independent of the particle shape, and can therefore be fixed using exact results for $d$-dimensional hyperspheres. We then have

$$
\begin{aligned}
{[\sigma(\text { conducting sphere })]_{\infty} } & =d \\
{[\sigma(\text { insulating sphere })]_{0} } & =d /(d-1), \\
{[\eta(\text { sphere })] } & =(d+2) / 2, \\
{[\eta] } & \approx[(d+2) / 2 d][\sigma]_{\infty},
\end{aligned}
$$

The $d=3$ versions of equations (5) and (6) are attributable to Maxwell and Einstein, respectively, while the results for arbitrary $d$ are attributable to Sangani and Brady, respectively [34-37]. The expression in equation (7) involves an angular averaging approximation and thus is not exact. However, it has been examined for cases in which either exact or numerically precise results are available, representing a broad range of shapes and polarizabilities (triaxial ellipsoids having arbitrary asymmetry [38], spherical dumbbell particles at arbitrary separation, elliptical particles in two dimensions, cubic dumbbells over a range of separations, circular and rectangular cylinders, "sponges," a square ring, a square hollow tube, and "jacks" [7]). Results for all these cases are illustrated in figures 1a-b for $d=3$ and $d=2$, respectively. Filled circles denote exact results and open circles indicate finite element calculations. Solid lines indicate equation (7) and the broken line in figure 1a corresponds to the 

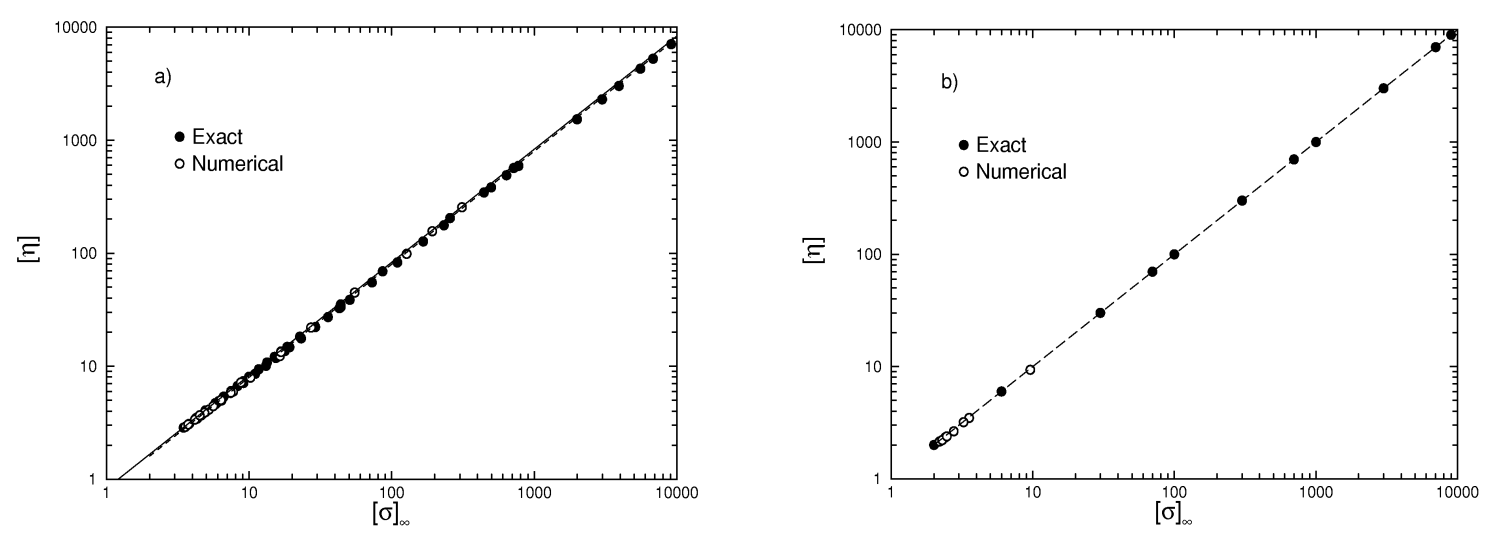

Figure 1. Intrinsic viscosity versus intrinsic conductivity of conducting particles. Solid lines denote the angular averaging prediction of Garboczi and Douglas [7], equation (7). The dashed line indicates the exact result for extended needle- and plate-shaped ellipsoids of revolution. (a) Exact $(\bullet)$ and finite element results (o) in three dimensions. Exact results are for triaxial ellipsoids, ellipsoids of revolution $[7,36]$, and dumbbells over a range of separations. The finite element calculations are for rectangular parallelepipeds, circular cylinders, "jacks," "sponges," square ring, dumbbell of cubes ("dice"), square hollow tubes in three dimensions and rectangles, a spherical lens and touching circles in two dimensions. (b) Exact (•) and finite element results (o) in two dimensions. Exact results are for ellipses and finite element calculations correspond to rectangular and polygonal regions.

ratio $[\eta] /[\sigma]_{\infty}=0.8$, the limit of needle and plate ellipsoids of revolution [7]. A compilation of $[\eta] /[\sigma]_{\infty}$ over extensive data for all these cases gives $[7]$

$$
[\eta] \approx(0.79 \pm 0.04)[\sigma]_{\infty}
$$

in three dimensions. The uncertainty interval indicates the maximum deviation from the average. A better approximation is obtained by using the prefactor 0.8 for slender particles and $5 / 6 \approx 0.833$ for less symmetric "globular" shapes [39]. Thus, equations (7) or (8) give estimates of $[\eta]$ valid to a relative uncertainty of around $5 \%$, which is less than or comparable to experimental uncertainty.

As defined above, $[\eta]$ and $[\sigma]$ are dimensionless. However, the intrinsic viscosity is conventionally defined relative to the mass concentration rather than the volume fraction $\phi$. Therefore, the conventional intrinsic viscosity is $[\eta]_{M}=\left(V_{p} / M\right)[\eta]$ for $M$ the mass of the body.

Consider now a particle moving through an inviscid fluid. Its motion induces motion in the fluid (even without viscosity), and the far-field disturbance is described by a dipolar field. The mass of the moving particle becomes equivalent to a hydrodynamic effective mass tensor $\mathbf{M}$ that is the sum of the bare mass and a "virtual mass" tensor $\mathbf{W}$,

$$
\mathbf{M}=V_{p} \mathbf{I}+\mathbf{W},
$$

where $\mathbf{I}$ is the identity matrix (the density of the particle and fluid are assumed to equal unity for simplicity of discussion here). It has been shown rigorously $[9,19]$ 
that $\mathbf{M}=-\boldsymbol{\alpha}_{m}$ so that the exact hydrodynamic-electrostatic analogy

$$
[\sigma]_{0}=\left[\operatorname{Tr}\left(\boldsymbol{\alpha}_{m}\right) / \mathrm{d} V_{p}\right]=-\left[\operatorname{Tr}(\mathbf{M}) / \mathrm{d} V_{p}\right]
$$

immediately follows [7]. This is, therefore, the counterpart of equation (7) to inviscid fluids. We finally note that the electrostatic counterpart of $\mathbf{W}$ is the polarization tensor (not to be confused with the polarizability tensors $\boldsymbol{\alpha}_{e}$ or $\boldsymbol{\alpha}_{m}$ ). The hydrodynamic virtual mass is thus a kind of fluid polarization associated with the motion of bodies in fluids.

\subsection{Analogies between capacity and friction coefficient}

The final electrostatic-hydrodynamic analogy that we consider is the relation between electrostatic capacity $C$ of a conducting particle and the translational friction coefficient $f$ of a Brownian particle of the same shape. $C$ is the proportionality constant between the charge and the potential of the conductor and is a functional of its shape. Our units are such that the capacity of a sphere in $d=3$ equals its radius. $C$ is obtained from solutions of Laplace's equation with Dirichlet boundary conditions. The friction coefficient $f$ of a Brownian particle is invariant to particle rotation since a diffusing particle samples all orientations as it moves over large distances. A formal angular averaging of the Oseen hydrodynamic interaction indicates that $f$ is proportional to $C,[2,3,5,40]$

$$
f \approx 6 \pi \eta \text { (dispersing liquid) } C .
$$

Therefore, within the angular averaging approximation, the capacity $C$ of a conducting particle equals the hydrodynamic radius $R_{\mathrm{H}}$ of a Brownian particle of the same shape, since this latter is conventionally defined as $f / 6 \pi \eta$. Comparison between equation (10) and existing analytic results shows that it is accurate to about $1 \%$ generally and often much better $[2,3]$. Equation (10) is exact for triaxial ellipsoids and a tabulation of exact values of $C(f)$ is given by Hubbard and Douglas [3]. There are many analogies relating $C$ exactly to other transport properties (thermal capacity, Smołuchowski rate constant for diffusion-limited reactions, scattering length in quantum theory and acoustics, etc.) so that the determination of $C$ has many further applications than those discussed in the present paper [2].

\section{Numerical path-integral calculation of electrical polarizabili- ty and capacity}

A classical result of probabilistic potential theory is that the capacity $C$ can be calculated formally by averaging over random walk trajectories [41]. More recently, the technique has been extended to the calculation of the polarizability tensor $\boldsymbol{\alpha}_{e}$ [17]. In fact, the two quantities $C$ and $\boldsymbol{\alpha}_{e}$ can be obtained simultaneously. (The tensor $\boldsymbol{\alpha}_{m}$ is formally amenable to similar treatment, but certain technical details render it more difficult). The "Zeno" algorithm [17], employed in these calculations, proceeds according to the following steps. 
(1) Refer to the surface of the object as $\Omega$. The object is enclosed within a sphere of radius $R$, the "launch" sphere. The final estimates are independent of the value of $R$ and the precise location of $\Omega$ within the launch sphere, but the best statistics are obtained if the smallest sphere that completely contains $\Omega$ is used. The origin of coordinates is taken to be the center of the launch sphere.

(2) A point $(x, y, z)$ is selected at random on the surface of the launch sphere to serve as the initiation site for a new random walk. Assign three charges, $c_{x}, c_{y}$, and $c_{z}$, to the walker. The $x$-charge $c_{x}$ is set at +1 with probability $(1+x / R) / 2$, and otherwise it is set to -1 , with similar definitions for the other two charges. The walk begins from this point and continues until it either hits $\Omega$ or wanders off to infinity. This is achieved by following the iterative procedure in step 3 .

(3) Given a point $\mathbf{P}$ on the exterior of $\Omega$, define the distance function $\rho(\mathbf{P}, \Omega)$ to be the minimum distance from $\Omega$ to $\mathbf{P}$. Let $\mathbf{P}$ represent the current position of the random walker. If $\mathbf{P}$ lies on or inside the launch sphere, then move the walker to an arbitrary point on the surface of the sphere whose center is $\mathbf{P}$ and whose radius is $\rho(\mathbf{P}, \Omega)$. If $\mathbf{P}$ lies outside the launch sphere and if $B$ represents its distance from the origin, let the walker escape to infinity with probability $1-R / B$; otherwise return it to the surface of the launch sphere at a point selected from the well known distribution for the sites of first passage of random walkers from an external point to the surface of a sphere. Iterate until the walker either escapes to infinity or until the distance $\rho$ falls below some small predetermined "skin thickness", $\varepsilon$, at which time the walker is taken to have hit $\Omega$. Just as in Zeno's celebrated paradox, the walker never actually reaches $\Omega$, but it comes arbitrarily close.

(4) Repeat from step 2 with a new random walker. Accumulate statistics on the number of hits and on the distribution of sites at which walkers of each particular charge configuration $\left(c_{x}, c_{y}, c_{z}\right)$ hit. These determine $C$ and $\boldsymbol{\alpha}_{e}$ according to formulas given elsewhere [17]. The technique is rigorous in the limit of a large number of walks and the limit $\varepsilon \rightarrow 0$. It has been verified on a large number of objects for which $C$ and $\boldsymbol{\alpha}_{e}$ can be obtained independently [17]. Since the algorithm is only rigorous in the limit $\varepsilon \rightarrow 0$, we can expect errors comparable to $\varepsilon$. Performance degrades, however, if we set $\varepsilon$ too small. We obtained excellent performance using values of $\varepsilon$ around $10^{-5}$ or smaller.

All dependence on $\Omega$ enters only through the distance function $\rho$. This makes the Zeno algorithm versatile: by assigning the computation of $\rho$ to a plug-in subroutine, we can switch from one body to another simply by switching the subroutine. Computation of $\rho$ for complex bodies is the bottleneck of the procedure, so computation times depend strongly on the complexity of the body. However, the present case, in which bodies were defined as unions of as many as 6400 individual spheres, was not too difficult; then computation of $\rho$ consists of computing the distance to each individual sphere and taking the minimum distance. We have also applied it to polyhedral surfaces [17], representing the surfaces as unions of triangles; then 


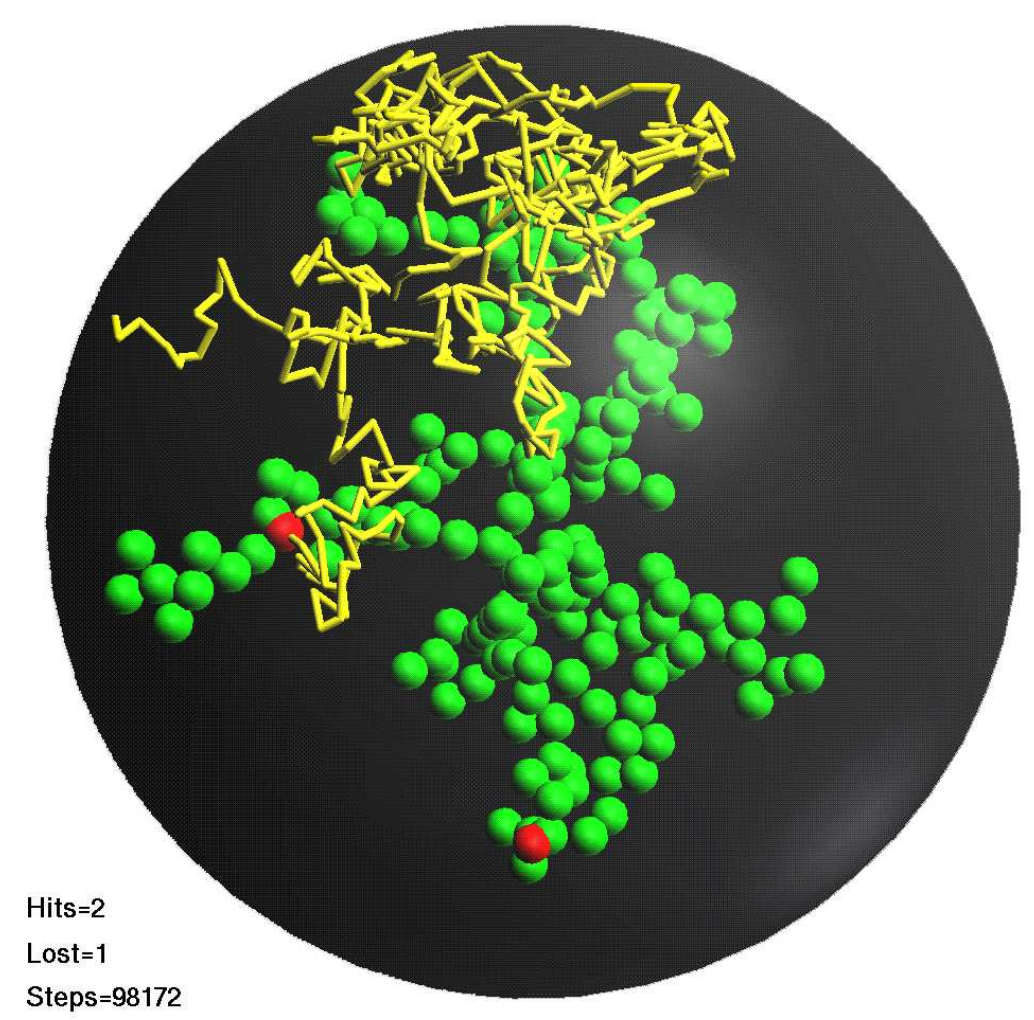

Figure 2. Illustrative realization of a random walk sampling path launched from an enclosing surface. The object in this case is a model branched polymer where spheres are placed at the vertices of the "graph" describing the polymer. The fraction of random walk trajectories that hit the polymer rather than the launch sphere determines the electrostatic capacity. The electrostatic polarizability tensor is obtained similarly except that the launched random walks are assigned charges according to the position from which they are launched (see text for details).

computation of $\rho$ is achieved by computing the distance to each triangle and taking the minimum distance.

\section{Illustrative calculations for linear and star polymers and DLA aggregates}

The hydrodynamic-electrostatic analogy is formally valid only for rigid molecules. For statistically defined objects such as flexible polymers and aggregates, we apply the "rigid-body" approximation: We generate an ensemble of independent structures, compute the capacity and the polarizability tensor for each member of the ensemble, and then take the hydrodynamic property to be the ensemble average. Exact calculation of the hydrodynamic properties of flexible molecules is much more difficult, but there are strong indications that the ensemble average over all possible conformations, each one treated as if it were rigid, is a good approximation to the 
exact hydrodynamics of the flexible molecule [65]. The reported averages, therefore, are of the capacity and of the diagonal components $\alpha_{\mathrm{ij}}$ of $\boldsymbol{\alpha}_{e}$ to obtain the scalar quantity $[\eta]_{M}$ of experimental interest.

\subsection{Linear polymers}

We have already considered linear polymers in a previous publication. However, it is customary to report the properties of star polymers in relation to linear polymers of the same total mass, (see below) and so it became necessary to extend those calculations to cover a greater set of chain lengths. We modeled linear polymers as chains of spherical beads, each bead having diameter 2 and each pair of contiguous beads required to be tangent. Non-contiguous beads are allowed to overlap. This model represents real polymer chains in solution at the theta temperature where attractive and repulsive intramolecular interactions largely compensate $[63,64]$. Ensembles containing 5000 statistically independent chains were generated for values of $N$ between 76 and 6401. We launched 1000 trajectories from an enclosing launch sphere at each chain in the ensemble. (See figure 2 for an illustrative example in which the target object is a non-equilibrium branched polymer [18].) We employed the Zeno algorithm with $\varepsilon=10^{-5}$. With only 1000 trajectories per chain, we estimate (by launching many more trajectories at a few chains) that there is 3 and $15 \%$ relative uncertainty in the capacity and polarizability components, respectively, for any one chain. Nevertheless, the ensemble averages $\langle C\rangle$ and $\langle\alpha\rangle$ should be much more accurate since each average involves at least $5 \cdot 10^{6}$ probe trajectories. Computational time is linear in $N$, the bottleneck at large $N$ being the computation of the function $D(\mathbf{r})$. Because of arbitrary overlap among spheres in the random walk chains, the volume $V_{p}$ is neither easy to compute nor constant throughout the ensemble. However, the value of $V_{p}$ is immaterial since it is more appropriate to consider the ensemble average of $[\eta]_{M}$.

Our results can be described well with the following expansions

$$
\begin{aligned}
\langle C\rangle & \cong 0.652 N^{1 / 2}+1.230-3.61 N^{-1 / 2} \\
\left\langle\operatorname{Tr}\left(\boldsymbol{\alpha}_{e}\right)\right\rangle & \cong 13.66 N^{3 / 2}+59.6 N-96.1 N^{1 / 2}
\end{aligned}
$$

where $\langle\ldots\rangle$ denotes an ensemble average.

We use the relations $\langle C\rangle \cong R_{\mathrm{H}}$ and equation 8 to estimate the hydrodynamic radius and intrinsic viscosity of polymer solutions. Results are expressed relative to the radius of gyration $R_{\mathrm{g}}$ of the chain (root mean-square distance of polymer segments from the center of mass $[63,66]$ ), which can be calculated exactly for this model [66],

$$
R_{\mathrm{g}}=(2 N / 3)^{1 / 2}\left[1-N^{2}\right]^{1 / 2} \approx(2 N / 3)^{1 / 2} .
$$

In figure $3 \mathrm{a}$ we show our data for the ratio $\psi_{h} \equiv R_{\mathrm{H}} / R_{\mathrm{g}}$ for the random walk chain model and the fitted line denotes the relation,

$$
\psi_{h}=0.798+1.506 N^{-1 / 2}-4.42 N^{-1}
$$



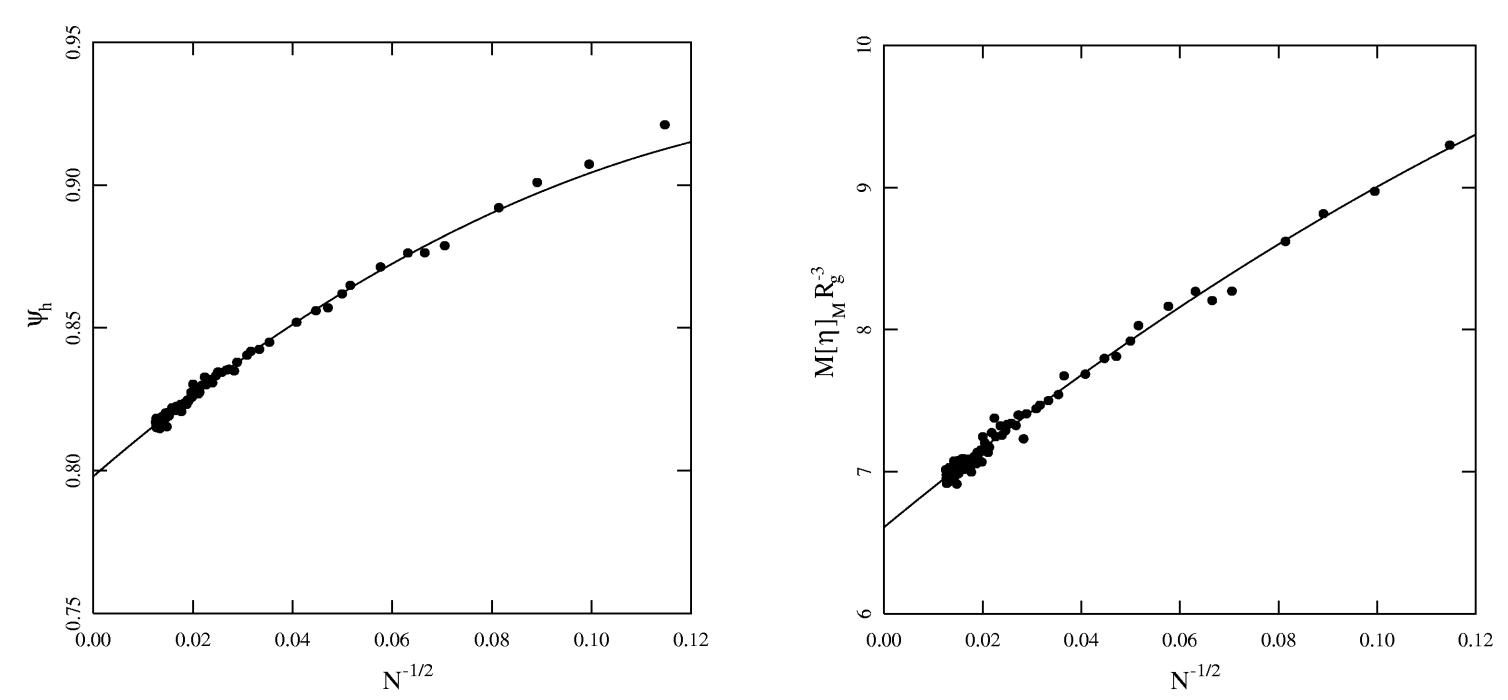

Figure 3. The hydrodynamic radius and intrinsic viscosity of polymer chains are estimated respectively from the electrostatic capacity $C$ and the mean polarizability trace $\operatorname{Tr}\left(\boldsymbol{\alpha}_{e}\right)$ of perfect conductors having the same shape as the polymer chains. The resulting estimates of $C / R g=\psi_{h}$ and $M[\eta]_{M} / R_{\mathrm{g}}^{3}$ are shown as functions of $N^{-1 / 2}$ in (a) and (b), respectively. The fitted curves (solid lines) are given by equation (14).

and similarly in figure $3 \mathrm{~b}$ our estimate of $[\eta]$ obtained from our polarizability calculation,

$$
M[\eta]_{M} R_{\mathrm{g}}^{-3}=\left[6.61+28.6 N^{-1 / 2}-46.5 N^{-1}\right](1.00 \pm 0.05) .
$$

The factor $(1.00 \pm 0.05)$ arises from the uncertainty in equation (8). The leading term in equation (28b) is often reported in terms of the "Flory-Fox number", $\Phi=$ $6^{-3 / 2}[\alpha]_{M} M N_{\mathrm{A}} / R_{\mathrm{g}}^{3}$, where $N_{\mathrm{A}}$ is Avogadro's number. Our estimate of $\Phi$ is then,

$$
\Phi=(2.71 \pm 0.14) \cdot 10^{23}
$$

where the uncertainty again arises from the $5 \%$ relative uncertainty in equation (8). The best experimental estimates for $\psi_{h}$ and $\Phi$ at the theta temperature are [67] $0.79 \pm 0.04$ and $(2.5 \pm 0.1) \cdot 10^{23}$. Our present estimates also closely correspond to calculations for flexible random walk chains based on the Kirkwood-Riseman hydrodynamic equations without the configurational preaveraging approximation $[65,68]$, $\psi_{h}(\mathrm{KR})=0.77 \pm 0.03$ and $\Phi(\mathrm{KR})=(2.59 \pm 0.18) \cdot 10^{23}$. (The stated uncertainties are estimates of sampling error. These values probably also contain systematic finite $N$ errors.) The leading term in equation (14a) is somewhat larger than the value $\psi_{h} \cong 0.77$ found in previous random walk simulations by Douglas et al. [2], in which the bead radius was one quarter of the bond length rather than one half and for which $N=101$. This discrepancy may be due to finite $N$ effects, even though this particular bead radius was employed because it exhibits relatively weak $N$ dependence. Further discussion of $\psi_{h}$ relative to previous theoretical estimates and measurements is given by Douglas and Freed [69]. 


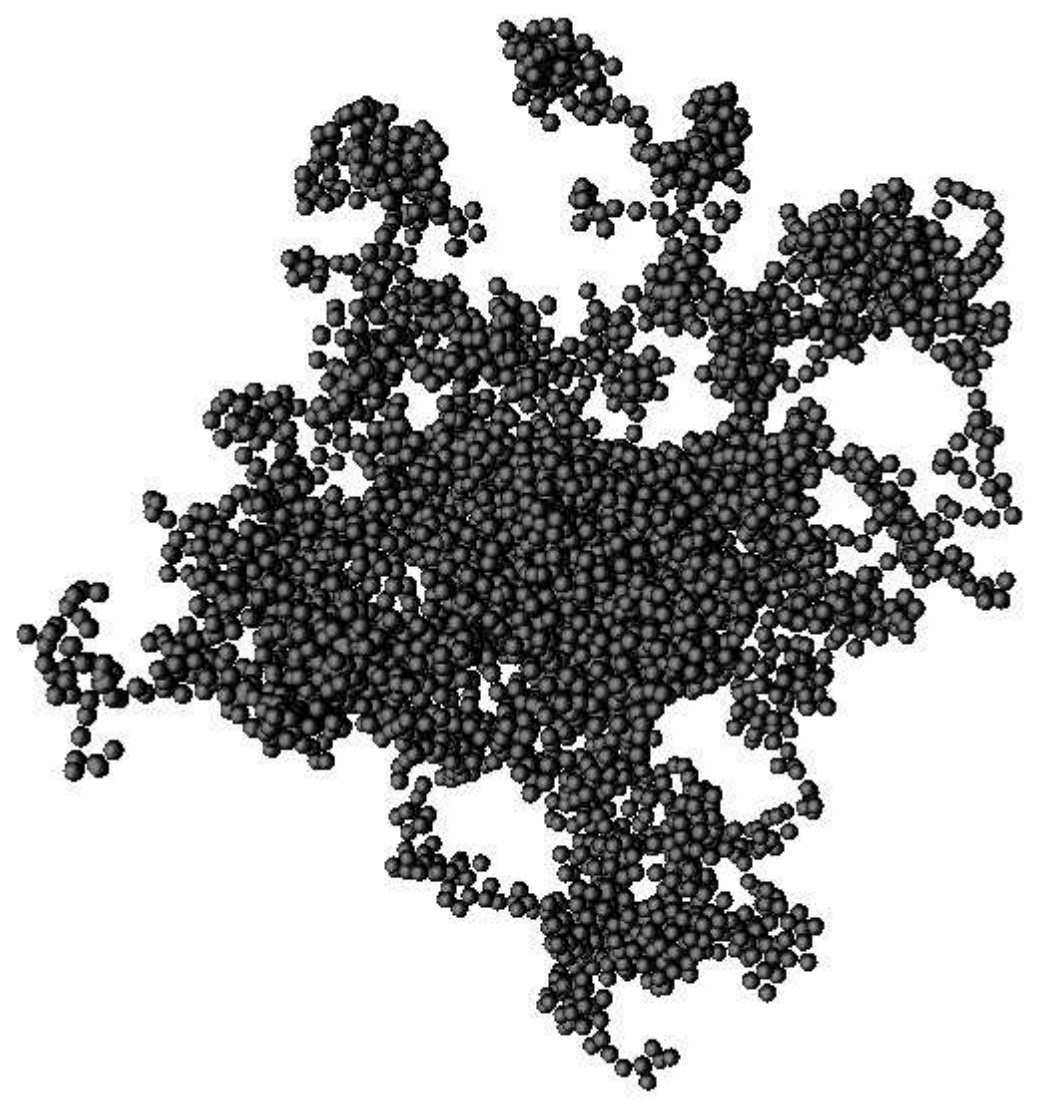

Figure 4. Representative image of a 12-arm star polymer containing $N=6001$ beads.

\subsection{Star polymers}

We modeled star polymers as $f$ different chains of $L$ beads, each one grafted by one end onto a central core bead. As with the linear polymer model, each bead has diameter 2 and contiguous beads are required to be tangent, but overlaps are permitted between non-contiguous beads. The total number of beads is $f L+1$ (the 1 contribution comes from the core bead, which is not considered to belong to any arm). Figure 4 shows a representative configuration for a 12-arm star polymer where $L=500$ for illustration. No reliable analytic methodology currently exists for calculating the transport properties of branched polymers so that this path integral formulation is especially useful in treating this type of problem.

The simulation protocols, including ensemble size, number of trajectories launched, and the skin size, were identical to those described above for linear chains. We generated ensembles with $f=3,4,5,6,10,12,20,40$, and 60 with $L$ between 25 and 1600 , but subject always to the constraint $f L \leqslant 6400$, that being the current practical limitation on the size of the model. The absolute magnitude of the various measures of polymer size are sensitive to details of the model, but ratios of large scale properties exhibit universality that can be exploited to discriminate between different types of molecular architectures [16]. We thus consider dimensionless ratios 

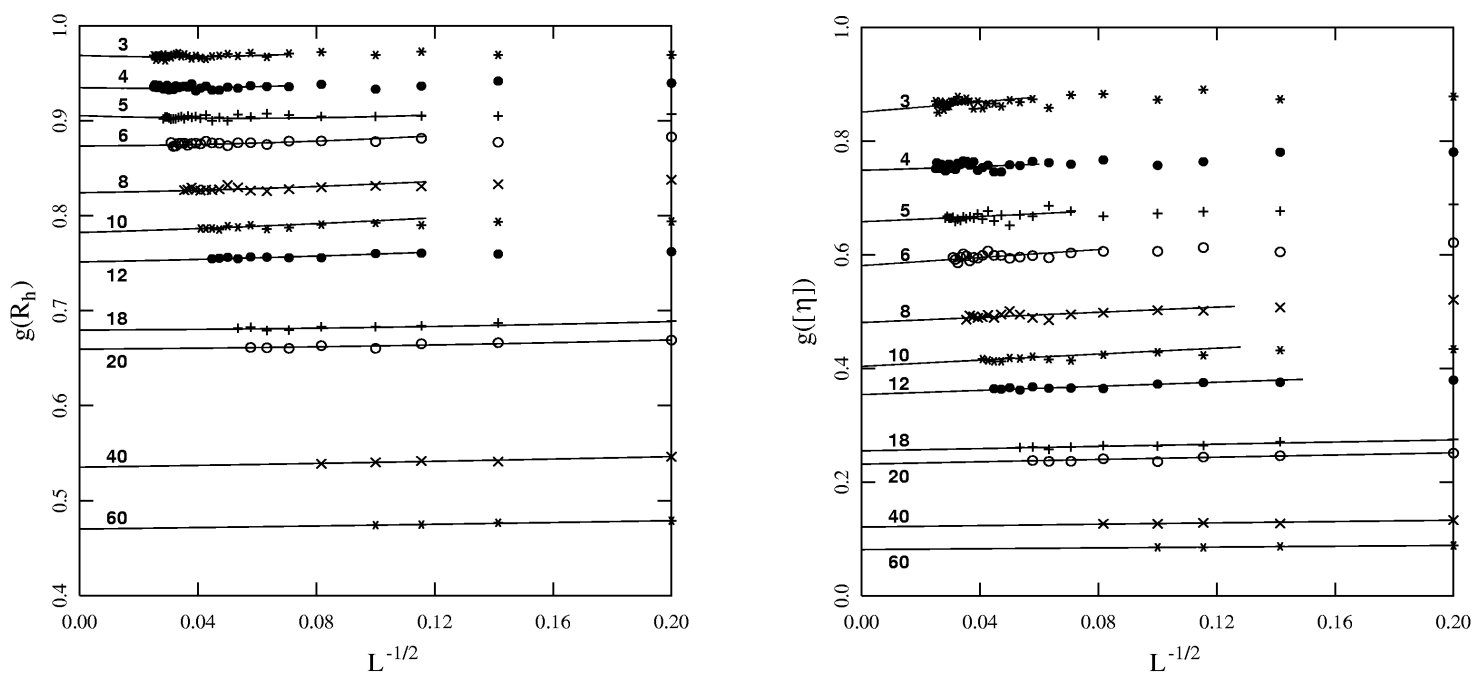

Figure 5. Hydrodynamic property ratios for star polymers as a function of arm length $L$. Numbers denote the number of arms. Solid curves are the extrapolation explained in the text. (a) $g\left(R_{\mathrm{H}}\right)$ vs. $L^{-1 / 2}$; (b) $g([\eta])$ vs. $L^{-1 / 2}$.

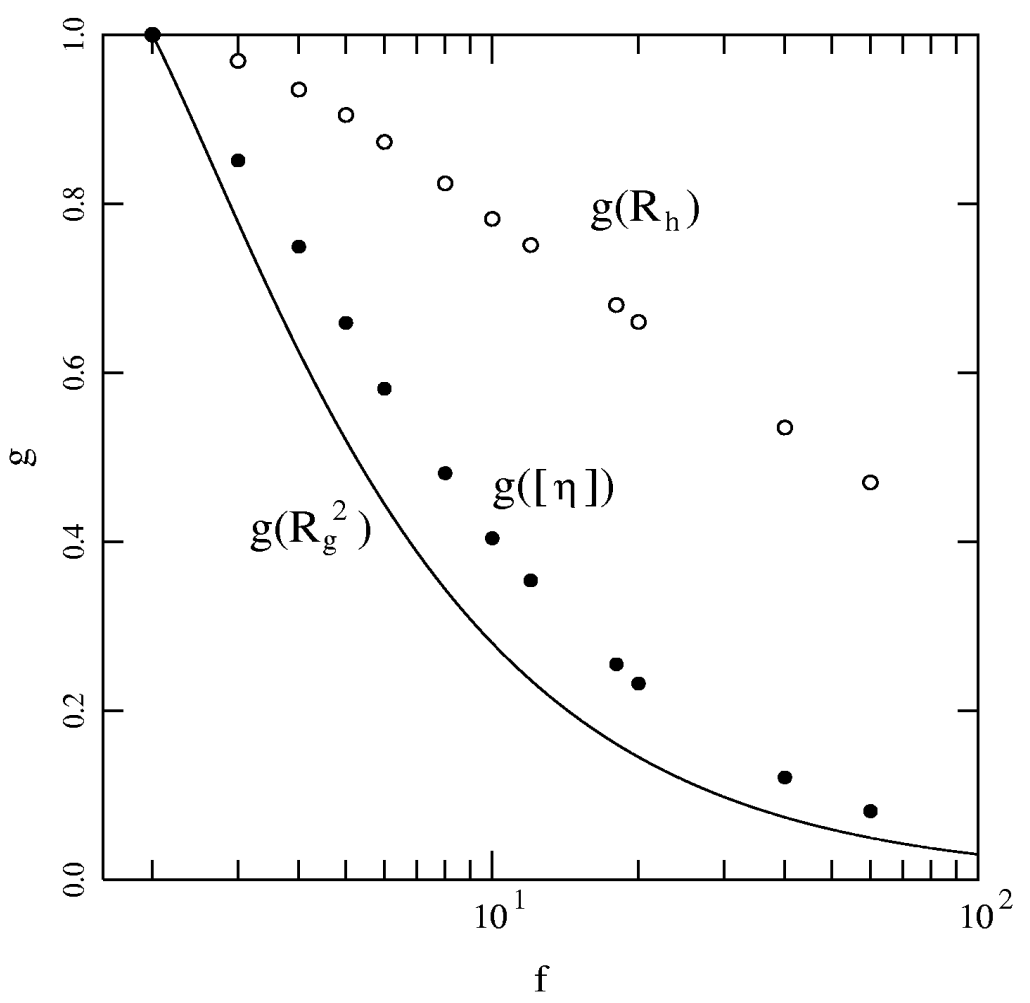

Figure 6. Dependence of $g\left(R_{\mathrm{g}}^{2}\right), g([\eta])$, and $g\left(R_{H}\right)$ on arm number, $f$. 
Table 2. Fitting parameters for star polymers.

\begin{tabular}{|l|l|l|l|l|}
\hline$f$ & $A_{1}$ & $B_{1}$ & $A_{2}$ & $B_{2}$ \\
\hline 3 & 1.094 & 1.081 & 60.4 & 182.2 \\
\hline 4 & 1.219 & 1.082 & 81.8 & 194.1 \\
\hline 5 & 1.320 & 0.964 & 100.5 & 230 \\
\hline 6 & 1.395 & 1.088 & 116.6 & 280 \\
\hline 8 & 1.520 & 1.096 & 148.6 & 299 \\
\hline 10 & 1.613 & 1.149 & 174.3 & 363 \\
\hline 12 & 1.697 & 1.048 & 201 & 360 \\
\hline 18 & 1.880 & 0.864 & 266 & 378 \\
\hline 20 & 1.923 & 0.866 & 283 & 405 \\
\hline 40 & 2.207 & 0.845 & 418 & 511 \\
\hline 60 & 2.374 & 0.772 & 516 & 537 \\
\hline
\end{tabular}

of properties, either two different properties of the same star model or the same property of a star and a linear polymer of the same total number of chain segments.

The first ratio of this type compares the radii of gyration of a star and a linear polymer [16,63],

$$
g\left(R_{\mathrm{g}}^{2}\right)=R_{\mathrm{g}}^{2}(\text { star }) / R_{\mathrm{g}}^{2}(\text { linear }) .
$$

For random walk chains of arm length $L$ this ratio is

$$
g\left(R_{\mathrm{g}}^{2}\right)=(1+L)[2+L(3 f-2)] /(1+f L)(2+f L) .
$$

The above expression becomes independent of chain length in the limit of infinite arm length [63],

$$
g\left(R_{\mathrm{g}}^{2}\right) \sim(3 f-2) / f^{2}, \quad L \rightarrow \infty .
$$

To obtain estimates of the corresponding ratios for the hydrodynamic radius $g\left(R_{\mathrm{H}}\right)$ and the intrinsic viscosity $g([\eta])$ we calculate the ratios $C / L^{1 / 2}$ and $\operatorname{Tr}\left(\boldsymbol{\alpha}_{e}\right) / L^{3 / 2}$ and fit our results to the scaling relation. We obtain our estimate of $g\left(R_{\mathrm{H}}\right)$ and $g([\eta])$ in the limit of long arm length $(L \rightarrow \infty)$ from the ratios of $C$ and $\operatorname{Tr}\left(\boldsymbol{\alpha}_{e}\right)$ for stars and linear polymers in the long chain limit [See equations (11) and (12) for the linear chain data in this comparison].

$$
\begin{aligned}
C / L^{1 / 2} & =A_{1}+B_{1} L^{-1 / 2}, \\
\operatorname{Tr}\left(\boldsymbol{\alpha}_{e}\right) / L^{3 / 2} & =A_{2}+B_{2} L^{-1 / 2} .
\end{aligned}
$$

The fitted values of $A_{1}, B_{1}, A_{2}$, and $B_{2}$ from the simulation data shown in figures $5 \mathrm{a}, \mathrm{b}$ are given in table 2. The $g$ ratios in the large $N$ limit are then given by ratios of the leading coefficients in equations (11), (12), (17), and (18). These are listed in table 3 and displayed in figure 6 . The result for values for $g\left(R_{\mathrm{g}}^{2}\right)$ were obtained from equation (16). It is obvious from figures $5 \mathrm{a}$ and $5 \mathrm{~b}$ that evaluation of $A_{1}$ and $A_{2}$ 
Table 3. $g$ ratio for star polymers.

\begin{tabular}{|c|c|c|c|c|c|}
\hline$f$ & $\begin{array}{c}g\left(R_{\mathrm{g}}^{2}\right) \\
\text { equation }(16)\end{array}$ & $\begin{array}{c}g\left(R_{\mathrm{H}}\right) \\
\text { our results }\end{array}$ & $\begin{array}{c}g(\eta) \\
\text { our results }\end{array}$ & $\begin{array}{c}g\left(R_{\mathrm{H}}\right) \\
{[70]}\end{array}$ & $\begin{array}{c}g([\eta]) \\
{[70]}\end{array}$ \\
\hline 3 & 0.778 & 0.969 & 0.851 & & \\
\hline 4 & 0.625 & 0.935 & 0.749 & & \\
\hline 5 & 0.520 & 0.905 & 0.659 & & \\
\hline 6 & 0.444 & 0.873 & 0.581 & $0.86 \pm 0.01$ & $0.58 \pm 0.02$ \\
\hline 8 & 0.344 & 0.824 & 0.481 & & \\
\hline 10 & 0.280 & 0.782 & 0.404 & & \\
\hline 12 & 0.236 & 0.751 & 0.354 & $0.75 \pm 0.01$ & $0.38 \pm 0.03$ \\
\hline 18 & 0.160 & 0.680 & 0.255 & $0.66 \pm 0.01$ & $0.24 \pm 0.03$ \\
\hline 20 & 0.145 & 0.660 & 0.232 & & \\
\hline 40 & 0.074 & 0.535 & 0.121 & & \\
\hline 60 & 0.049 & 0.470 & 0.081 & & \\
\hline
\end{tabular}

requires a relatively broad extrapolation, especially for larger values of $L$. Therefore, the $g$ values given in table 3 and in figure 6 are subject to some uncertainty.

We observe that the ratios $g\left(R_{\mathrm{g}}^{2}\right), g\left(R_{\mathrm{H}}\right)$ and $g([\eta])$ decrease monotonically with the number of chain arms $f$. This general trend reflects the increasingly compact nature of the polymer chain arising from the branching constraint. The extent of the change is property dependent and collectively these ratios provide a useful means for discriminating branching architecture [16].

There have been previous estimates of these ratios by alternative methods for ideal ("Gaussian") chains for a limited number of cases of arm number by alternative bead model calculations of the hydrodynamic properties using methods that avoid the substantial configurational preaveraging approximation [70]. We include these former estimates of $g\left(R_{\mathrm{H}}\right)$ and $g([\eta])$ in table 3 for comparison. Both types of estimates agree to within statistical uncertainty. These calculations also agree within statistical uncertainty with the estimate of $\psi_{h}$ for linear chains, as noted above. This internal consistency between such different methods of calculation is very encouraging support for both methods. We note, however, that it is easy to incorporate polydispersity in the shape and size of polymer beads, side branch structures and other realistic features of the chain structure into the path-integration calculations without substantial increase in computational complexity and these generalizations would be rather involved in other methods of computation.

\subsection{Diffusion-limited cluster growth without excluded volume interactions}

Diffusion-limited aggregation (DLA) is an important model for particle aggregation under conditions far from equilibrium when particles stick irreversibly to a grow- 
ing cluster and the flux of the particles to the cluster is determined by diffusion [18]. In general, clusters can form either under equilibrium or non-equilibrium conditions and a variety of 'universality classes' (diffusion vs. reaction limited non-equilibrium clusters, linear vs. lattice animal equilibrium polymers, etc.) arise depending on growth conditions. Knowledge of the dimensionless invariants that describe these clustering types should be useful in differentiating these dynamic clustering processes. The probabilistic computational method should be especially useful in this type of problem because it avoids the use of slender body point source model calculations (e.g. the Kirkwood-Riseman model [68]) that are more appropriate for slender polymer chains than for relatively compact polymer clusters.

DLA clusters are generated according to the following formal algorithm [18]. A sphere of unit radius is placed at the origin and becomes the first sphere of the growing cluster. A point-like random walker diffuses in from a great distance and stops when it first makes contact with this sphere. The second sphere is then added to the growing cluster so that it is tangent to the first sphere at the point of the first contact. A second point-like random walker then diffuses in until it makes first contact with either of the two spheres. The next sphere is then added to the cluster so as to be tangent to the surface at that point. This process continues until the cluster has grown to the desired size. Obviously, this growth process can be performed with just a minor variation of the Zeno algorithm. However, this procedure involves a simplification from the algorithm described above where the random walkers are required to diffuse-in from a "great distance". At each iteration, we construct a new launch sphere centered at the origin and having radius just sufficiently large to completely enclose all spheres currently in the cluster. Any random walker approaching from a great distance must first make contact with this sphere and so we do not have to start tracking its trajectory until it does. In other words, the random walkers are actually initiated from arbitrary sites on the surface of a sphere just large enough to enclose the cluster. From that point on, the trajectory is generated just as in the Zeno algorithm. As designed, this algorithm allows for overlap of the spheres in the growing clusters, and therefore our clusters differ from conventional DLA clusters. (We term our clusters theta-DLA clusters to distinguish them from their volume exclusion counterparts.) Figure 7 shows a representative example of a theta-DLA cluster corresponding to $N=5000$ spheres having a unit radius.

The capacity (hydrodynamic radius) and the electrical polarizability (intrinsic viscosity) were estimated using the "Zeno" algorithm [17]. We generated independent ensembles for each cluster size $(N)$ containing 5000 configurations and 1000 walkers were launched at each cluster within each ensemble. The $N$ values were chosen to be 100, 150, 200, 250, 300, 400, 500, 700, 850, 1000, 1500, 2000, 2500, 3000, 4000, 5000 and 6400 . The computational time increased substantially with $N$ and the simulation took about 1 week on a PC for the $N=6400$ ensemble, although it was considerably faster at smaller $N$.

The usual measures of aggregate size, viz., $C, R_{\mathrm{g}}$, and $\operatorname{Tr}\left(\boldsymbol{\alpha}_{e}\right)^{1 / 3}$, scale as $N^{0.40}$. Figure 8 a shows our estimates of the ratio $C / R_{\mathrm{g}}$ for the non-equilibrium aggregates. It is apparent that the finite size $N$ corrections are large in this model. The ratio 


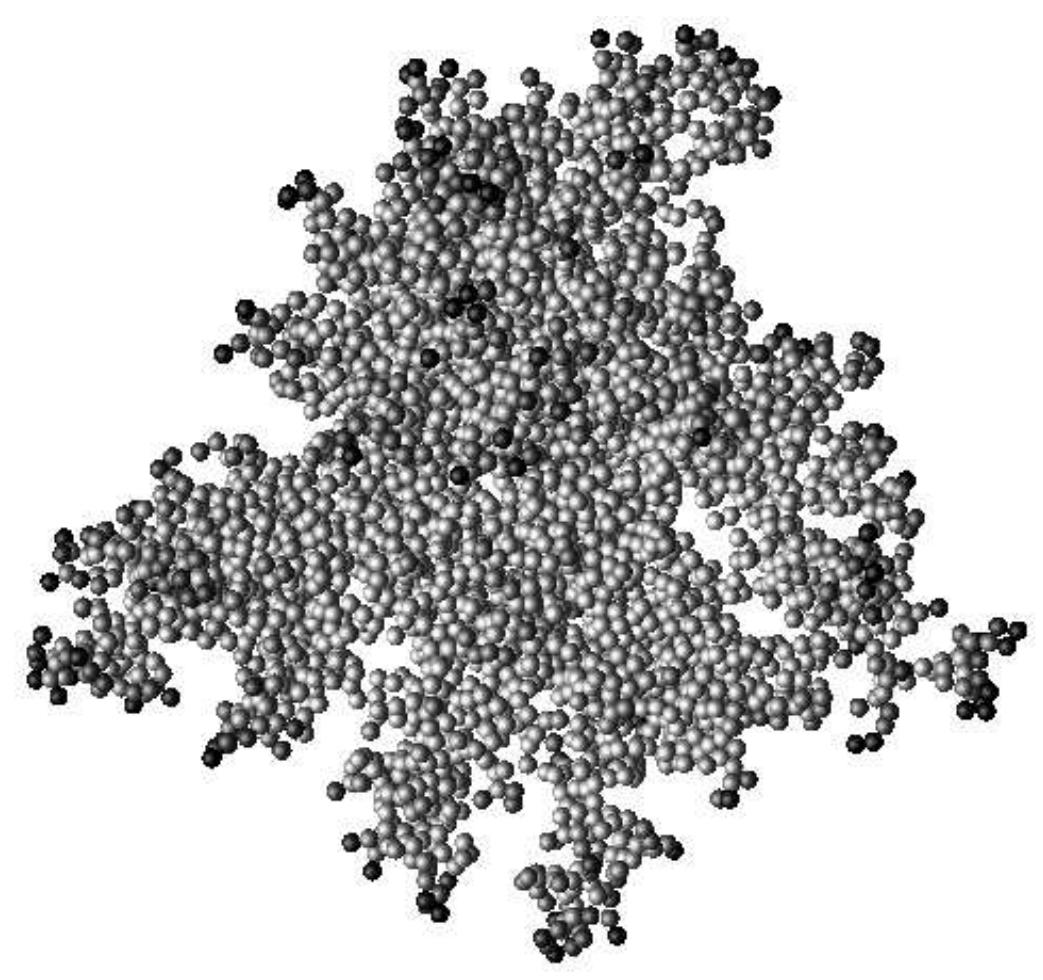

Figure 7. Illustration of a theta diffusion-limited aggregation cluster. $N=5000$.
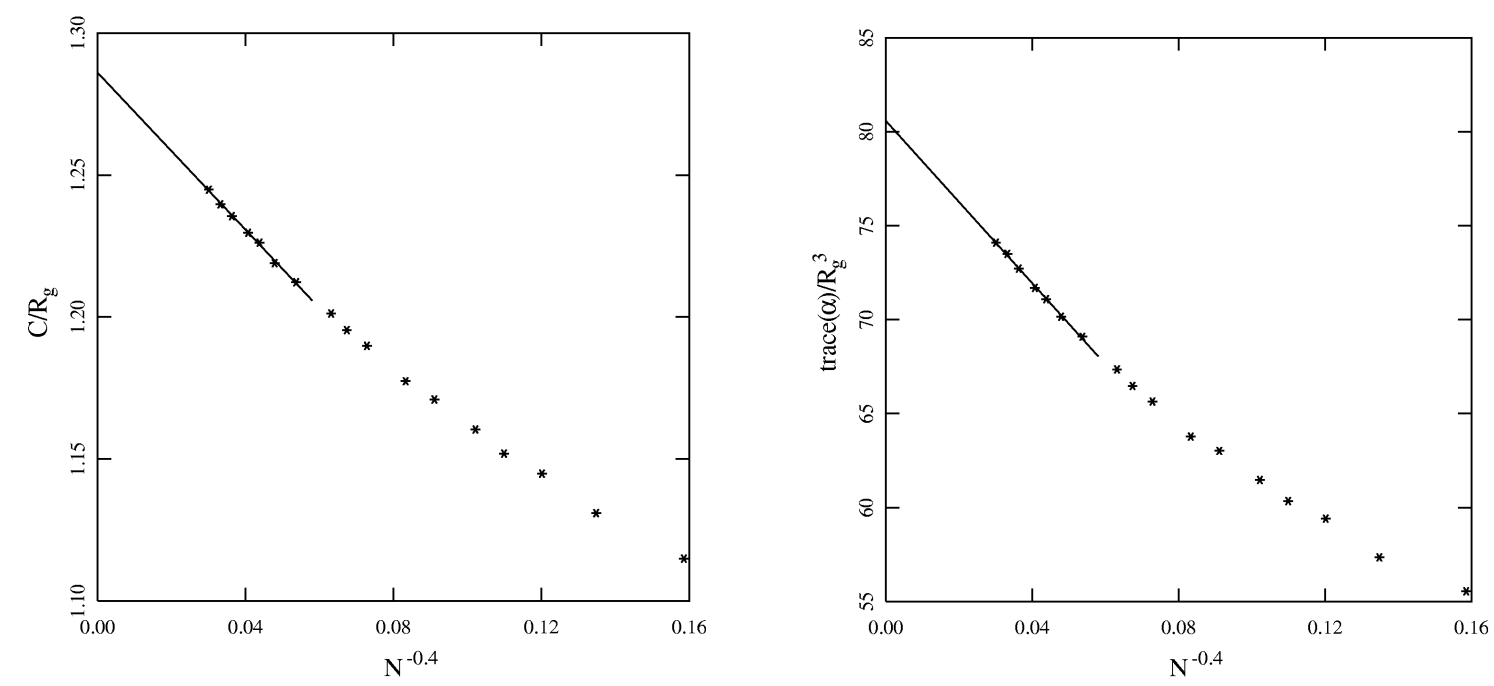

Figure 8. Estimates of (a) $C / R_{\mathrm{g}}=R_{\mathrm{H}} / R_{\mathrm{g}}=\psi_{h}$ and (b) $\operatorname{Tr}\left(\boldsymbol{\alpha}_{e}\right) / R_{\mathrm{g}}^{3}$ for thetaDLA clusters as a function of $N^{-0.4}$, where $N$ is the cluster mass. 


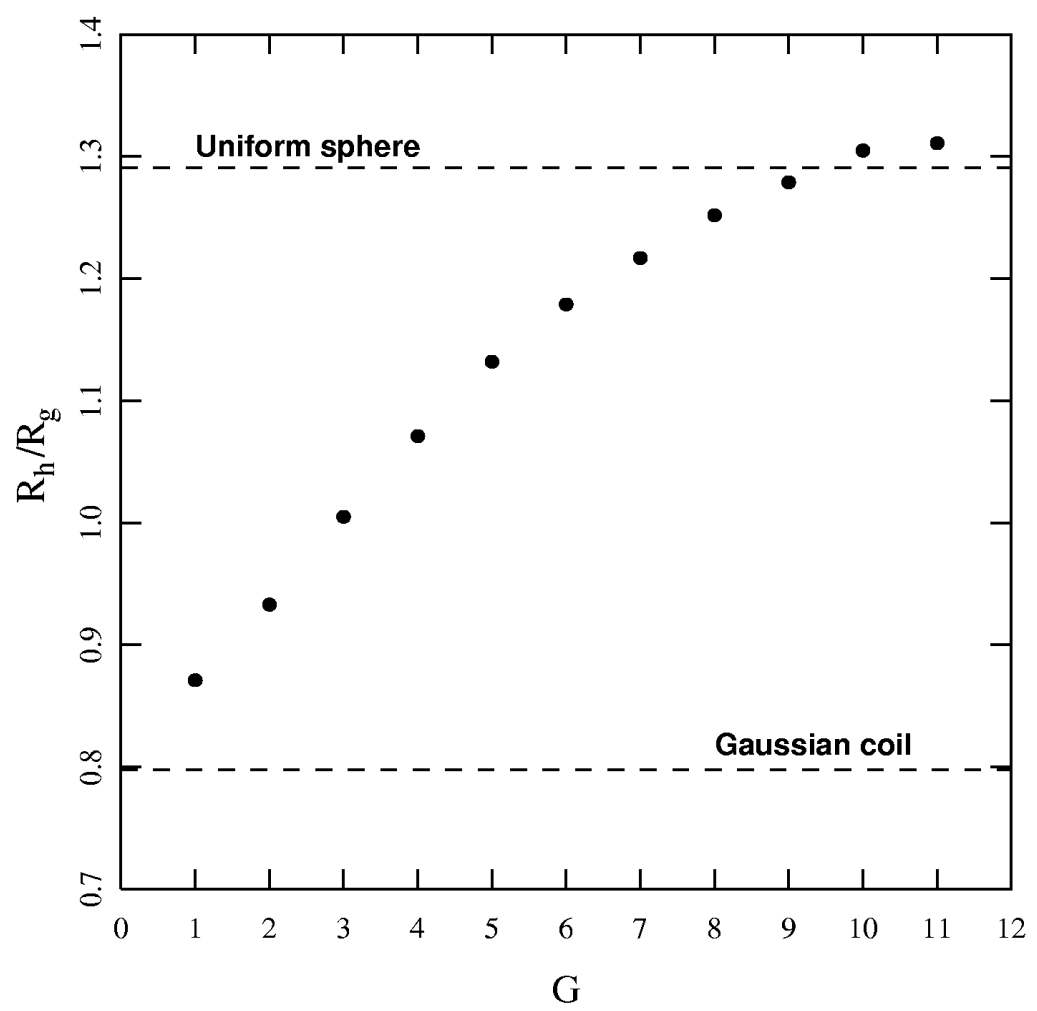

Figure 9. Influence of generation number $G$ on the ratio $R_{\mathrm{H}} / R_{\mathrm{g}}$ for dendrimer branched polymers.

$\psi_{h}=C / R_{\mathrm{g}}$ seems to extrapolate to a value near 1.28 , near the exact value for hard spheres, $(5 / 3)^{1 / 2} \approx 1.29$. This strongly suggests that the diffusion-limited clusters are approaching a relatively compact configuration in the limit of large cluster mass $N$. The ratio $\operatorname{Tr}\left(\boldsymbol{\alpha}_{e}\right) / R_{\mathrm{g}}^{3}$ is shown in figure $8 \mathrm{~b}$, and extrapolates to a value of around 80 or more. The large value indicates that while the cluster may have a compact overall shape, the cluster is "porous", leading to a substantial increase of $[\eta]$ relative to a uniform hard sphere.

We remind the reader again that our clusters neglect self-excluded volume interactions and that repulsive interactions should make the aggregates more diffuse, leading to a reduction of $\psi_{h}$. Chen et al. have estimated the $R_{\mathrm{H}} / R_{\mathrm{g}}$ for diffusionlimited cluster-cluster aggregates and this ratio to equal 0.875 , independent of cluster size [71]. The deviation from our result found in these calculations (which included self-excluded volume interactions) seems to be rather large.

Dendrimer molecules are highly branched polymers grown through a successive addition of multifunctional monomers (See [42] for illustration of their topological form, [73] for general discussions of dendrimers.) During construction of each generation, multifunctional groups are added so that, unlike the theta-DLA, the topological structure is nearly perfect. At low generation number $G(G<4)$ in their recursive synthesis, the molecules resemble flexible star polymers and we can expect similarities to the flexible polymer calculations of the previous section. At higher $G(G>4)$ 
the branching constraints begin to predominate and structures with relatively high local segmental densities form which we can expect to have some similarities to the densely branched DLA clusters. In figure 9 we show our previously obtained results for $\psi_{h}$ as a function of $G$ [17]. Consistent with the discussion above, the magnitude of $\psi_{h}$ is similar to those for flexible polymer chains when $G$ is small and to the uniform sphere values $\left(\psi_{h} \cong 1.29\right)$ when $G$ is large. (Technically speaking, $\psi_{h}$ for these molecules should not exceed the value for uniform spheres. That it does in the higher generations is a consequence of the fact that one of the radii is computing assuming point-like contributions from each bead, while the other assumes the beads have finite volume.) These results all indicate a crossover from a random coil-like structure to a compact structure with increasing $G$. As in the case of DLA aggregates, the intrinsic viscosity of the dendrimer molecules is estimated to have a value much larger than a sphere, consistent again with a sponge-like structure rather than a uniform density sphere.

\subsection{Influence of branching on the equilibrium charge distribution}

There has been much interest in characterizing the multifractal properties of branched polymers determined by the scaling of moments of the equilibrium charge distribution with the mean polymer size [72]. Despite the extensive analytic work,

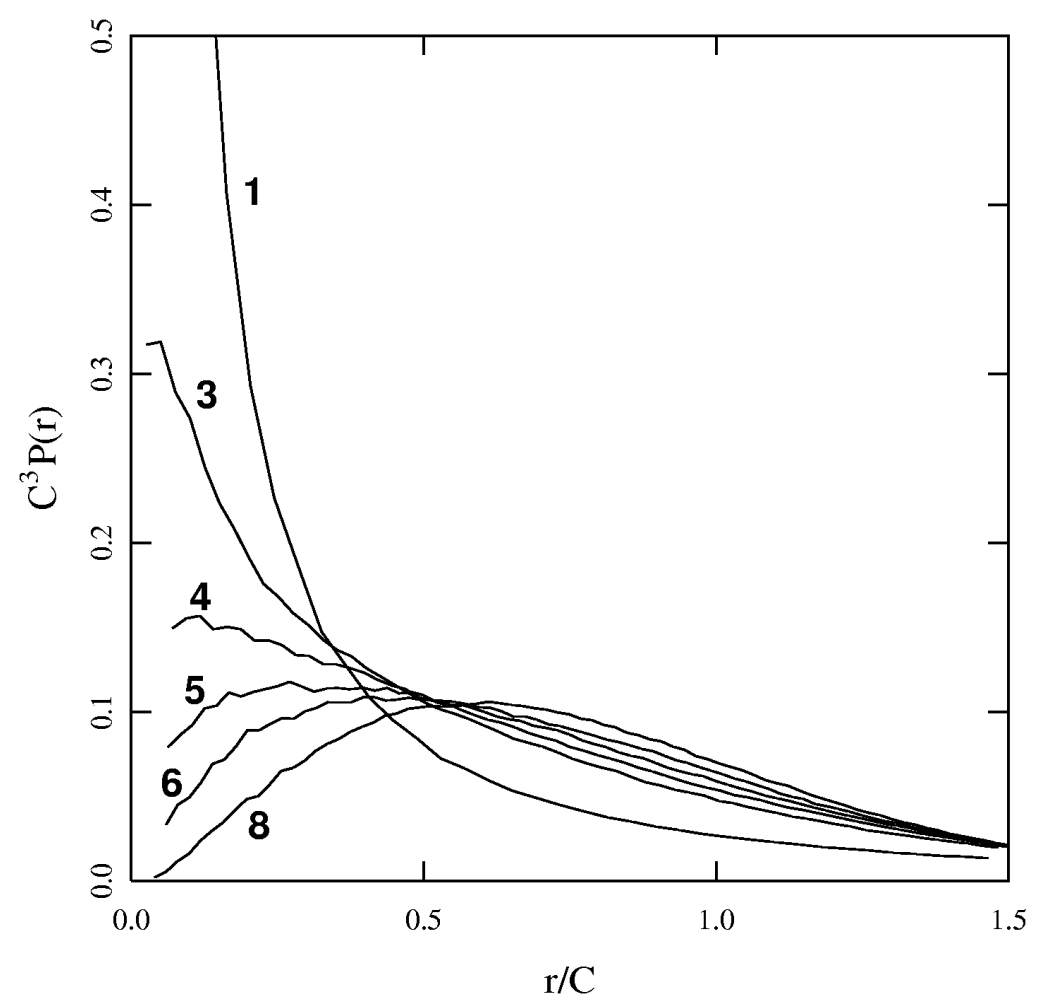

Figure 10. Influence of the number of star arms $f$ on the radially averaged charge density $P(r)$ of random walk chains. The charge distribution is averaged about the center mass of the polymer. Note occurrence of peak in density for $f>4$. 
there is very little computational investigation of the charge distribution on model branched polymers such as stars and dendrimers which can be used to test the validity of the analytic theory or even to understand the qualitative nature of the resulting charge distributions on such structures. In this section, we take a first quick look at these distributions as a prerequisite to examining the multifractal spectra of regular branched polymers (stars and dendrimers).

First, in figure 10 we show the radially averaged equilibrium charge distribution $P(r)$ of random walk star polymers having 6401 beads and arms of equal length for $f=1,3,4,5,6,8$. The ensemble averaging is as described in section 4.2 above. The radial coordinate $r$ is normalized by natural scale $C$ governing the effective size of the star polymers in the decay of the electrostatic field at large distances. $P(r)$ is multiplied by a corresponding $C^{3}$ volume normalization factor. We observe that the maximum of the equilibrium charge density occurs near the origin in the stars with $f \leqslant 4$, but the maximum moves out to an increasing value of $r / C$ as the number of star arms increases. For small $f$, the charge distribution can be fitted by a power law for small $r / C$ (e.g., $-3 / 2$ for linear chains and $-1 / 2$ for $f=3$ ) and the exponent becomes near zero for $f=4$ (near uniform charge distribution). This qualitative change in the equilibrium charge distribution with $f$ does not seem to have been appreciated before.

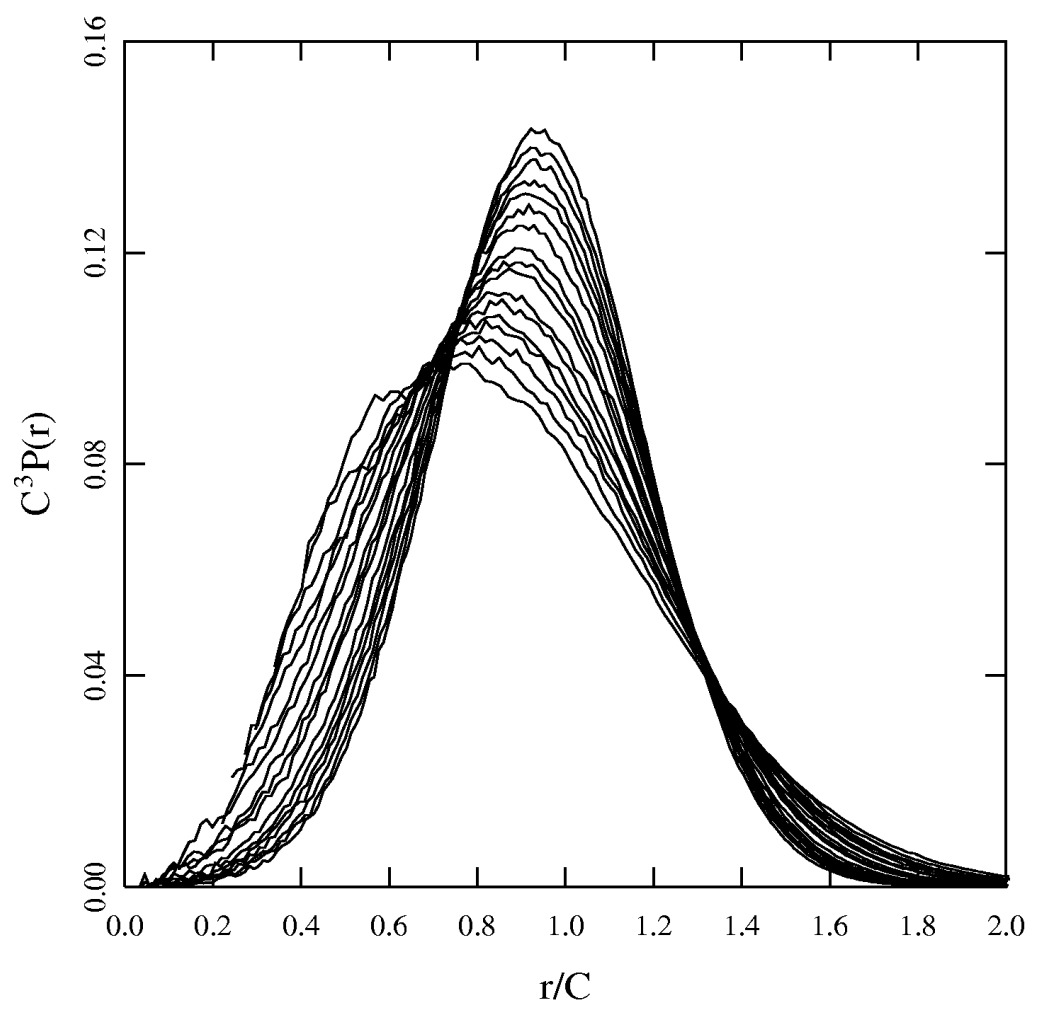

Figure 11. Influence of cluster mass on the radially averaged charge density $P(r)$ of theta-DLA clusters. The charge distribution is averaged about the center mass of the polymer. 
The development of a maximum in the equilibrium charge distribution is also a conspicuous feature of our theta-DLA aggregates. For the same range of $N$ values and chain ensembles as described in section 4.3, we see in figure 11 that the distribution of $P(r)$ about its cluster center of mass in this case becomes increasingly peaked and apparently more Gaussian as $N$ increases. We find that the variance $\sigma$ of the unreduced distribution increases as $\sigma \sim N^{0.29}$. But since $C \sim N^{0.40}$, the reduced distribution of figure 11 becomes narrower with increasing $N$.

The origin of this transition in the character of the charge distribution is clear. For a compact sphere the charge distribution reduces to a delta function on the boundary of the sphere and for diffuse objects there is a penetration depth describing the extent that diffusing species can enter into the domain before capture occurs. The peak in $P(r)$ means that the domain defined by the many-arm $(f>4)$ star and theta-DLA branched polymer have well-defined "boundaries", albeit diffuse ones. The absence of the peak means the chains segments in the interior are very strongly exposed.

This change in the nature of the charge distribution has many potential ramifications. In the case of the drag forces on these objects the (angularly averaged) momentum force distribution on the polymer should follow the equilibrium charge distribution [3] so that drag forces on a steadily moving polymer should become more concentrated on the central region of the polymer in the case of linear chains, but become concentrated on a well-defined polymer periphery in the case of highly branched polymers. This change also has significance of the diffusion-limited binding of associating groups onto polymer structures, i.e., linear chains can be more readily penetrated along the entire chain length, but branched polymers largely screen the interior structure so that binding becomes concentrated on the polymer exterior. Further research is needed to fully understand this dramatic change in charge distribution with branching morphology and its physical ramifications. The pathintegration method should be a useful tool in this type of study that seems to be beyond existing analytical methods.

\section{Conclusion}

We have applied a numerical path-integration algorithm to the calculation of the capacity $C$ and electric polarizability $\boldsymbol{\alpha}_{e}$ of star polymers and aggregates grown under diffusion-limited conditions. Excluded volume interactions are not included in these model polymer structures and the calculations assume the polymers are conducting. These shape functionals have many applications to the scattering of light and sound and are also important for describing effective properties of particle dispersions and transport properties of macromolecules. We first summarize the previously obtained results for translational friction coefficient and intrinsic viscosity of flexible linear (random walk) polymers and then generalize to star polymers containing $f$ arms of equal length. Ratios of the star properties to those of linear polymers are then calculated since these "universal" ratios are commonly utilized experimentally to characterize branching morphology. Good agreement is obtained with pre- 
vious simulations of random walk stars based on completely different computational methods. The results for regular stars were then compared with non-equilibrium clusters grown according to a diffusion-limited aggregation model. These aggregates ignore repulsive interactions between attaching spheres, so we term these theta-DLA aggregates. We find that the ratio of the capacity $C$ to the radius of gyration of these aggregates approaches a value close to that for a sphere in the limit of large mass, suggesting these objects become increasing compact as they grow. The previously obtained results for hierarchically branched dendrimer molecules (having the topology of a Cayley tree, but having repulsive excluded volume interactions between the polymer segments) show a similar trend with increasing generation number $G$, the ratio of the capacity $C$ to the radius of gyration changes from a value close to random coil chain at low $G$ to a value close to a sphere for large $G$. Increasingly branched growth again leads to a tendency to form compact polymer structures.

We also investigate the influence of branching topology on the equilibrium charge distribution in $f$-arm star and theta-DLA clusters. The radially averaged charge distribution about the chain center of mass changes it qualitative character with an increasing number of star arms, i.e., exhibiting a maximum near the chain center of mass for stars having 4 or less arms and a maximum at a finite value of $C / r$ ( $r$ the distance from the center of mass of the cluster) for larger $f$. The theta-DLA clusters exhibit a maximum in the charge density near $C / r=1$ and the variance of this distribution decreases as the cluster grows and becomes gradually more compact. These results indicate that the "interior" of linear chains (central chain segments) are much more "exposed" than the central segments in highly branched polymers (many arm stars and DLA aggregates). This is an important qualitative aspect of the charge distribution in polymers that has many potential physical ramifications and which deserves further systematic study.

\section{Acknowledgement}

We thank Terence Griffin of the Mathematical and Computational Science Division (Scientific Application and Visualization Group) at the National Institute of Standards and Technology for preparing the images of star and theta-DLA aggregates.

\section{References}

1. Douglas J.F., Friedman A. Coping with Complex Boundaries. - In: IMA Series on Mathematics and its Applications, vol. 67. New York, Springer, 1995, p. 166.

2. Douglas J.F., Zhou H.-X., Hubbard J.B. // Phys. Rev. E, 1994, vol. 49, p. 5319.

3. Hubbard J.B., Douglas J.F. // Phys. Rev. E, 1993, vol. 47, p. 2986.

4. Zhou H.-X., Szabo A., Douglas J.F., Hubbard J.B. // J. Chem. Phys., 1994, vol. 100, p. 3821; Luty B.A., Mc Cammon J.A., Zhou H.-X. // J. Chem. Phys., 1992, vol. 97, p. 5682; Given J.A., Hubbard J.B., Douglas J.F. // J. Chem. Phys., 1997, vol. 106, p. 3761 . 
5. Douglas J.F. // Adv. Chem. Phys., 1997, vol. 102, p. 121.

6. Hunt F.Y., Douglas J.F., Bernal J. // J. Math. Phys., 1995, vol. 36, p. 2386.

7. Douglas J.F., Garboczi E.J. // Adv. Chem. Phys., 1995, vol. 91, p. 85; Roberts A.P., Garboczi E.J. The elastic moduli of porous ceramic models. // J. Amer. Ceram. Soc. (in press); Garboczi E.J., Douglas J.F. The effect of aggregate shape and properties on composite concrete properties. (in preparation).

8. Garboczi E.J., Douglas J.F. // Phys. Rev. E, vol. 53, p. 6169.

9. Strutt J.W. ("Lord Rayleigh") // Phil. Mag., 1897, vol. 44, p. 28.

10. Keller J.B., Kleinman R.E., Senior T.B.A. // J. Inst. Appl. Math., 1974, vol. 9, p. 14.

11. Senior T.B.A. // Radio Sci., 1976, vol. 11, p. 477; Kleinman R.E., Senior T.B.A. // Radio Sci., 1972, vol. 7, p. 937; Senior T.B.A., Kleinman R.E. // IEEE Trans. Aerospace and Elect. Syst., 1975, vol. 11, p. 672; Jones D.S. // J. Inst. Math. Applic., 1979, vol. 23, p. 421; Angel T.S., Kleinman R.E. // Radio Sci., 1982, vol. 22, p. 1120; Lee K.S.H. // Radio Sci., 1987, vol. 22, p. 1235; Dassios G., Kleinman R.E. // SIAM Rev., 1989, vol. 31, p. 565.

12. Van Bladel J. // J. Sound Vibrat., 1967, vol. 6, p. 386; ibid., 1968, vol. 8, p. 186; Van Bladel J. // J. Acoust. Soc., 1968, vol. 44, p. 1069; Senior T.B.A. // J. Acoust. Soc., 1973, vol. 53, p. 742; Jones D.S. // Proc. Roy. Soc. Edin. A, 1979, vol. 83, p. 245; Fabrikant V.I., // J. Sound Vib., 1986, vol. 111, p. 742; ibid., 1988, vol. 121, p. 1.

13. Bethe H. // Phys. Rev., 1944, vol. 66, p. 163; Bouwkamp C.J. // Rep. Progr. Phys., 1954, vol. 17, p. 35; Van Bladel J. // Radio Sci., 1979, vol. 14, p. 319; DE Meulenaere F., Van Bladel J. // IEEE Trans. Ant. Prop., 1977, vol. 25, p. 198; Jaggard D.L., Papas C.H. // Appl. Phys., 1978, vol. 15, p. 21; Cohn S.B. // Proc. IRE, 1951, vol. 39, p. 1416; Cohn S.B. // J. Appl. Phys., 1949, vol. 20, p. 257; ibid., 1951, vol. 22, p. 628; Okon E.K., Harrington R.F. // IEEE Trans. Electromagn. Compat., 1981, vol. 23, p. 359; Avras E. IEEE Trans. Ant. Prop., 1983, vol. 31, p. 719; Mc Donald N.A. IEEE Trans. Microwave Theor., 1985, vol. 33, p. 1146; ibid., 1987, vol. 35, p. 20; Fabrikant V.I. // J. Phys. A, 1987, vol. 20, p. 323.

14. Van Bladel J. // J. Sound Vib., 1967, vol. 6, p. 386; ibid., 1968, vol. 8, p. 186; Williams W.E. // J. Sound Vib., 1970, vol. 13, p. 37; Fabrikant V.I. // J. Sound Vib., 1988, vol. 121, p. 1; De Smedt R. // J. Sound Vib., 1981, vol. 75, p. 371.

15. Pólya G., Szegö G. Isoperimetric inequalities in mathematical physics. - In: Annals of Mathematics Studies, No. 27. Princeton, Princeton University Press, 1951; Payne L.E. // SIAM Rev., 1967, vol. 9, p. 453.

16. Douglas J.F., Roovers J., Freed K.F. Macromolecules, 1990, vol. 23, p. 4168.

17. Mansfield M.L., Douglas J.F., Garboczi E.J. Intrinsic viscosity and the electrical polarizability of arbitrarily shaped objects. // Phys. Rev. E., 2002, vol. 64, p. 061401.

18. Meakin P. Phase Transitions, 1988, vol. 12, p. 336, and references therein.

19. The "hydrokinetic analogy" relating the hydrodynamics of inviscid fluids and the theory of magnetic is utilized extensively by Kelvin. See: Thompson W.M. ("Lord Kelvin") Reprints on Electricity and Magnetism. London, MacMillan, 1884, Sects. 16-17 and Article 32.

20. Taylor G.I. // Proc. Roy. Soc. London A, 1928, vol. 120, p. 13; ibid., 1928, vol. 120 , p. 260; Birkoff G. Hydrodynmics: A Study of Logic, Fact and Similitude. Priceton, NJ, Princeton University Press, 1960, Chapt. 6.; Pólya G. // Proc. Natl. Acad. Sci. (USA), 1947, vol. 33, p. 218; Szegö S. // Duke Math J., 1949, vol. 16, p. 209; Moullin E.B. // Proc. Phys. Soc., 1928, vol. 29, p. 400; Cook G. // Phil. Mag., 1920, vol. 34, p. 350; 
Thompson K. // Am. J. Phys., 1988, vol. 56, p. 1043.

21. Roscoe R. // Phil. Mag., 1949, vol. 40, p. 338; Jain D.L., Kanwal R.P. // J. d' Anal. Math., 1972, vol. 25, p. 107.

22. Kanwal R.P. // J. Fluid Mech., 1960, vol. 10, p. 17.

23. Payne L. E. // Q. Appl. Math., 1952, vol. 10, p. 197; Weinstein A. // Bull. Amer. Math. Soc., 1953, vol. 50, p. 20; Payne L.E., Weinstein A. // Pacific J. Math., 1960, vol. 2, p. 633; Weiss G.W., Payne L. E. // J. Appl. Phys., 1954, vol. 25, p. 1321.

24. Heaviside O. // Phil. Mag., 1887, vol. 23, p. 10.

25. Strutt J.W. ("Lord Rayleigh") Theory of Sound, Vol. 2. New York, Dover, 1945; Tuck E.O. // Adv. Appl. Math., 1974, vol. 14, p. 89.

26. Hasimoto H. // J. Phys. Soc. Jpn., 1958, vol. 13, p. 633; Wang C.Y. // Phys. Fluids A, 1993, vol. 5, p. 1113 .

27. Wallis G. // Multiphase Sci. Tech., 1976, vol. 5, p. 239; Smereka P., Milton G.W. // J. Fluid Mech., 1991, vol. 233, p. 65; Sangani A.S., Zhang D.Z., Prosperetti A. // Phys. Fluids A, 1991, vol. 3, p. 2955; Cai X., Wallis G.B. // Phys. Fluids A, 1993, vol. 5, p. 1614.

28. Strutt J.W. ("Lord Rayleigh") Theory of Sound, Vol. 1. New York, Dover, 1945; Hill R., Power G. // Quart. J. Mech. Appl. Math., 1956, vol. 9, p. 313; Guth E. // J. Appl. Phys., 1945, vol. 16, p. 21; Chong J.S., Christiansen E. B., Baer A.D. // J. Polym. Sci., 1971, vol. 15, p. 2007; Phan-Thien N. // J. Elast., 1993, vol. 32, p. 243; Hunter S.C. // Proc. Ed.. Math Soc., vol. 15, p. 55; Gordon M., Hunter S.C., Love J.A., Ward T.C. // Nature, 1968, vol. 217, p. 735; Kanwal R.P. // Q. J. Appl. Math., 1955, vol. 8, p. 146; Jhon M.S., Metz R.J., Freed K.F. // J. Stat. Phys., 1988, vol. 52 , p. 1325.

29. Batchelor G.K. // Ann. Rev. Fluid Mech., 1974, vol. 6, p. 227.

30. Torquato S. // Appl. Mech. Rev., 1991, vol. 44, p. 37.

31. Fixman M. // J. Phys. Chem., 1984, vol. 88, p. 6472.

32. Jackson J.D. // Classical Electrodynamics. 2nd ed. N.Y., Wiley, 1975; Stratton J.A. Electromagnetic Theory. N.Y., Mcgraw-Hill, 1941.

33. Lakhtakia A. // Chem. Phys. Lett., 1990, vol. 174, p. 583.

34. Batchelor G.K. // J. Fluid Mech., 1970, vol. 41, p. 545; Batchelor G.K. // J. Fluid Mech., 1971, vol. 46, p. 813; Batchelor G.K., Green G.K. // J. Fluid Mech., 1972, vol. 56, p. 375; Rallison J.M. // J. Fluid Mech., 1978, vol. 88, p. 529; Jeffrey D.J., Acrivos A. // AICHE, 1976, vol. 22, p. 417; Kim S., Lu S.-Y. // Int. J. Multiphase Flow, 1987, vol. 13, p. 837; Pakdel P. // J. Rheol., 1991, vol. 35, p. 797.

35. Maxwell J.C. A Treatise on Electricity and Magnetism. N.Y., Dover, 1954.

36. Sangani A.S. // SIAM J. Appl. Mat., 1990, vol. 50, p. 64.

37. Einstein A. // Ann. Phys., 1906, vol. 19, p. 289; ibid., 1911, vol. 34, p. 591; Brady J.F. // Int. J. Multiphase Flow, 1984, vol. 10, p. 113.

38. Haber S., Brenner H. // J. Coll. Int. Sci., 1984, vol. 97, p. 496; Rallison J.M. // J. Fluid Mech., 1978, vol. 84, p. 237.

39. A slender body is taken to have at least one of the dimensions governing the scale of the body to be smaller than the largest scale by at least a factor of 5 . A globular body is more symmetric in shape and we arbitrarily define such a body to have relative dimensions that do not differ more than $50 \%$.

40. The combination of bounds on the sedimentation coefficient. Weinberger H. F. // J. Fluid Mech., 1972, vol. 52, p. 321 of non-skew bodies of general shape and Brenner's 
expression [Brenner H. // Adv. Chem. Phys., 1966, vol. 6, p. 287] relating $f$ to the average of the reciprocal diagonal components of the translational friction tensor indicates the bound, $f \geqslant 6 \pi \eta$ (dispersing liquid) $C$ for non-skew bodies. Rigorous bounds of the matrix elements of the shearing matrix in terms of $C$ and the components of $\boldsymbol{\alpha}_{e}$ [Nir A., Weinberger H.F., Acrivos A. // J. Fluid Mech., 1979, vol. 68, p. 739] have also been obtained.

41. Hunt G.A. // Trans. Amer, Math. Soc., 1956, vol. 81, p. 294; Erdös P., Taylor S.J. // Acta Math. Acad. Sci. Hung., 1960, vol. 11, p. 137; Ito K., Mckean // J. Math., 1960, vol. 4, p. 119; Ciesielsky Z. // Bull. Acad.. Polon. Sci., Math., Astron., Phys., 1964, vol. 12, p. 265; Chung K.L. // Ann. Inst. Fourier, 1973, vol. 23, p. 313; Spitzer F. // Z. Wahr., 1964, vol. 3, p. 110; Kac M. // Rocky Mt. J. Math., 1974, vol. 4, p. 3.

42. Mansfield M.L. // Macromolecules, 2000, vol. 33, p. 8043.

43. Schiffer M., Szegö G. // Trans. Amer. Math. Soc., 1949, vol. 67, p. 130.

44. Belevitch V., Boersma J. // Phillips J. Res., 1983, vol. 38, p. 79.

45. Felderhof B.U., Palaniappan D. // J. Appl. Phys., 1999, vol. 86, p. 6501; // J. Appl. Phys., 2000, vol. 88, p. 4947.

46. Goto E., Shi Y., Yoshida N. // J. Comp. Phys., 1992, vol. 100, p. 105.

47. Smythe W.W. // J. Appl. Phys., 1962, vol. 33, p. 2966; Taylor T.T. // J. Res. NBS, 1960, vol. 64B, p. 135; See also: Wang P.Q. // IEEE Trans. Ant. Prop., 1984, vol. 32, p. 956.

48. Taylor T.T. // J. Res. NBS, 1960, vol. 64B, p. 199.

49. Brown C.S. // Computers Math. Applic., 1990, vol. 20, p. 43.

50. Vattulainen I., Ala-Nissila T., Kankaala K. // Phys. Rev. A, 1995, vol. 52, p. 3205.

51. Reitan D., Higgins T.J. // J. Appl. Phys., 1951, vol. 22, p. 223.

52. Pólya G. // Amer. Math. Month., 1947, vol. 54, p. 201.

53. Given J.A., Hubbard J.B., Douglas J.F. // J. Chem. Phys., 1997, vol. 106, p. 3761.

54. Russell A. // Proc. Phys. Soc., 1925, vol. 37, p. 1925; Poisson // Mem. de l' Instit., 1811, vol. 1, p. 1; ibid., 1811, vol. 2, p. 163.

55. Cochran G.D. A New Experimental Test of Coulomb's Law of Force. University of Michigan, 1967 (doctoral dissertation).

56. Edwards T.W., Van Bladel J. // Appl. Sci. Res., 1961, vol. 9B, p. 151; See also: Mei K., Van Bladel J. // IEEE Trans. Ant. Prop., 1963, vol. 11, p. 52.

57. Herrick D.F., Senior T.A. // IEEE Trans. Ant. Prop., 1977, vol. 25, p. 590; Shiffer M. // C.R. Acad. Sci. 1957, Paris, vol. 244, p. 3118; Payne L.E., Weinberger H.F. // Bull. Amer. Math. Soc., 1953, vol. 59, p. 244.

58. Eyges L., Gianino P. // IEEE Trans. Ant. Prop., 1979, vol. 27, p. 557.

59. Kostant B. // Notices AMS, 1995, vol. 42, p. 959.

60. Jeans J. The Mathematical Theory of Electricity and Magnetism. London, 5th ed. Cambridge University Press, London, 1941.

61. Reitan D.K., Higgins T.J. // Trans. AIEE, Part 1, vol. 75, p. 761.

62. Solomon L. Compt. Rend. // Acad. Sci. (Paris), 1964, vol. 258, p. 64.

63. Yamakawa H. Modern Theory of Polymer Solutions, N.Y., Harpers, 1969.

64. De Gennes P.-G. Scaling Concepts in Polymer Physics. Ithaca, N.Y., Cornell University Press, 1979.

65. Zimm B.H. // Macromolecules, 1980, vol. 13, p. 592; de la Torre J.G., Jimenez A., Freire J. // Macromolecules, 1982, vol. 15, p. 148.

66. Flory P.J. Statistical Mechanics of Chain Molecules. New York, Wiley Interscience, 
1969.

67. Schmidt M., Burchard W. // Macromolecules, 1981, vol. 14, p. 210; Park S., Chang T., Park I.H. // Macromolecules, 1991, vol. 24, p. 5729; Miyaki Y., Einaga Y., Fujita H., Fakuda M. // Macromolecules, 1980, vol. 13, p. 588.

68. Kirkwood J.G., Riseman J. // J. Chem. Phys., 1948, vol. 16, p. 565.

69. Wang S.Q., Douglas J.F., Freed K.F. // J. Chem. Phys., 1986, vol. 85, p. 3674; ibid., 1987, vol. 87, p. 1346; Douglas J.F., Freed K.F. // Macromolecules, 1994, vol. 27, p. 6088 .

70. Freire J.J., Prats R., Pla J., de la Torre G.J. // Macromolecules, 1984, vol. 17, p. 1815; Freire J.J., Rey A., de la Torre G.J. // Macromolecules, 1984, vol. 17, p. 1815.

71. Chen Z., Meakin P., Deutch J.M. // Phys. Rev. Lett., 1987, vol. 59, p. 2121.

72. Cates M. E., Witten T.A. // Phys. Rev. A, 1987, vol. 35, p. 1809; von Ferber C., Holovatch Y. // Phys. Rev. E, 1999, vol. 59, p. 6914; Hentschel H.G.E., Procaccia I. // Physica D, 1983, vol. 8, p. 435; Lee J., Stanley H.E. // Phys. Rev. Lett., 1988, vol. 61, p. 2945.

73. Tomalia D.A., Hedstrand D.M., Wilson L.R. Encyclopedia of Polymer Science and Engineering. 2nd ed. NY, Wiley, 1990; Mourey T.H., Turner S.R., Frechet J.M.J., Hawker C.J., Wooley K.L. // Macromolecules, 1992, vol. 25, p. 2401.

\title{
Обчислення властивостей переносу зіркових полімерів і обмежених дифузією тета-агрегатів методом інтегрування за траєкторіями
}

\author{
М.Л.Менсфілд ${ }^{1}$, Дж.Ф.Дуґлас ${ }^{2}$ \\ 1 Кафедра хімії та хімічної біології, \\ Технологічний інститут Стівенса, Хобокен, Нью Джерсі 07030, США \\ 2 Відділ полімерів, Національний інститут стандартів і технології, \\ Гайтерсбург, MD 20899, США
}

Отримано 7 грудня 2001 р.

Хоча розрахунок властивостей переносу частинок складної форми (сталих швидкості Смолуховського для обмежених дифузією реакцій, коефіцієнтів тертя Стокса, віріальних коефіцієнтів для провідності, в'язкості й інших властивостей переносу) є в принципі безпосереднім, точне обчислення цих величин для об'єктів загальної форми представляє собою класичну за важкістю задачу. У даній роботі ми ілюструємо недавно розвинутий чисельний метод інтегрування за траєкторіями, щоб оцінити основні властивості переносу представлених об'єктів складної форми, які представляють науковий і технологічний інтерес (наприклад, зіркові полімери і обмежені дифузією агрегати без виключених об'ємних взаємодій). Методологія застосовується до об'єктів по суті довільної форми, і її застосовність для певних геометрій, де відомі точні результати, описана в попередній статті. Тут ми обчислюємо електростатичну єм- 
ність і тензор електричної поляризованості цих модельних зіркових полімерів, і тоді використовуємо точні і наближені властивості електростатично-гідродинамічних зв'язків, щоб оцінити коефіцієнт трансляційного тертя Стокса і віріальні коефіцієнти для провідності та зсувної в'язкості (внутрішньої провідності та в'язкості відповідно). Розглядаються безмасові відношення цих властивостей переносу і рівноважні масштаби розміру частинок (радіус гірації), оскільки ці відношення важливі у визначенні макромолекулярної топологічної структури та класу універсальності. Ми також обговоримо і проілюструємо вплив гілчастої архітектури на рівноважний розподіл заряду ("рівноважний розмір") цих розгалужених полімерів, де вони трактуються як провідники. Знайдено неочікувану якісну зміну в роподілі заряду із зростанням кількості гілок у зірковому полімері, що може мати важливі фізичні наслідки.

Ключові слова: тертя Стокса, сприйнятливість, внутрішня в'язкість, розгалужені полімери, інтегрування за траєкторіями, імовірнісна теорія потенціалу

PACS: 05.40.-a, 05.60.Cd, 36.20. $-r, 47.11 .+j, 66.20 .+d, 66.10 . C b$, 77.22. $-d, 87.15 . V_{V}$ 